\title{
DiOITOS
}

Revista de Comunicación Digital

\section{Estéticas activistas: cultura mediática y resonancia en las movilizaciones contemporáneas}

\section{Activist aesthetics: media culture and resonance in contemporary mobilizations}

\author{
Dorismilda Flores-Márquez \\ dfloresm@delasalle.edu.mx \\ Universidad De La Salle Bajío
}

\section{Resumen}

En los años recientes hemos visto la circulación de símbolos comunes en distintas movilizaciones alrededor del mundo, tal es el caso de la máscara de $V$ for Vendetta, los disfraces de personajes de Star Wars o The Handmaid's Tale o la performance de "Un violador en tu camino". Este artículo presenta una reflexión teórica sobre la presencia de elementos de la cultura mediática en el activismo, mediante la apropiación y la creación de símbolos. A la luz de estas manifestaciones, se propone una revisión de los conceptos de cultura mediática, resonancia, expresión pública y estéticas activistas, así como sus articulaciones. Esto contribuye a la comprensión de la dimensión simbólica del activismo en la era global.

\section{Palabras clave}

cultura mediática, expresión pública, resonancia, activismo, estéticas activistas

\begin{abstract}
In recent years, we have witnessed the circulation of common symbols in different mobilizations around the world, such as the mask of $V$ for Vendetta, the costumes of Star Wars or The Handmaid's Tale, or the performance "A rapist in your way". This article presents a theoretical reflection about the presence of media culture elements in the activism, through the appropriation and creation of symbols. In the light of these manifestations, I propose a revision of the concepts of media culture, resonance, public expression and activist aesthetics, as well as their articulations. This contributes to the understanding of the symbolic dimension of activism in the global age.
\end{abstract}

\section{Keywords}

media culture, public expression, resonance, activism, activist aesthetics

Recibido: 07/01/2020

Aceptado: 18/03/2020

Cómo citar este artículo:

Flores-Márquez, D. (2020).Estéticas activistas: cultura mediática y resonancia en las movilizaciones contemporáneas. Dígitos. Revista de Comunicación Digital, 6: 181-196. DOI: 10.7203/rd.v1i6.175 

en las movilizaciones contemporáneas

\section{Introducción}

La máscara de $V$ for Vendetta, el saludo de Hunger Games o los disfraces de personajes de distintas películas, han aparecido en las movilizaciones de los años recientes. Junto a esto, hay otra serie de símbolos que han sido creados en y para las protestas, que circulan a través de los medios y son apropiados en diferentes lugares del mundo. Unos y otros se vuelven parte importante de los movimientos y son comprendidos más allá del contexto inmediato. Estos elementos son relevantes para el estudio tanto de los movimientos sociales como de la comunicación.

Este artículo presenta una reflexión teórica sobre la presencia de elementos de la cultura mediática en el activismo, que se manifiesta a través de dos lógicas principales: por un lado, la apropiación de símbolos que provienen de los medios y el arte; por otro, la creación de símbolos en contextos específicos de protesta, que después se expanden hacia otros lugares. Como se verá más adelante, algunos de los casos que se señalan son muy recientes, lo cual implica que no hay suficiente distancia para el análisis. Sin embargo, se consideran aquí de manera exploratoria, para contribuir a la documentación de ellos, así como para abrir otras vías y preguntas de investigación.

En el texto se revisan, en primer lugar, los conceptos de cultura mediática, resonancia, expresión pública y estéticas activistas. En seguida, se identifican algunos casos de apropiación y creación de símbolos en las movilizaciones. Finalmente, se reflexiona sobre la dimensión simbólica del activismo en la era global.

\section{Elementos para el estudio de las estéticas activistas}

La presencia de movimientos sociales en contextos sociohistóricos específicos permite identificar una serie de rupturas y diferencias en los modos de entender el mundo, que se traducen en necesidades de cambio y se distinguen principalmente a partir de sus lógicas y la época, lo cual representa un desafío para su estudio. Particularmente, los movimientos sociales post-2010 han emergido en distintos lugares del mundo con demandas específicas, pero coinciden en un desplazamiento en los modos de ejercer y comprender el compromiso cívico y el activismo.

En primer lugar, se trata de movimientos que se organizan en red, tanto hacia el interior - para organizar las movilizaciones-como hacia el exterior - para expresarse públicamente y/o vincularse con activistas en otras ciudades-. En estos procesos, los medios digitales ganan centralidad, tanto por las posibilidades de comunicación instantánea que ofrecen, como porque son elementos clave en la vida cotidiana de los participantes. En segundo lugar, los movimientos emergen y defienden preocupaciones locales, al mismo tiempo que se insertan en discusiones globales, sobre problemáticas comunes, como derechos humanos, género, medio ambiente y justicia social. En 
tercer lugar, hay una articulación entre las actividades que se realizan en las calles y plazas públicas y aquello que se hace en internet, sea para difundir información, sea para apoyar en línea. Finalmente, se observa la utilización de símbolos compartidos alrededor del mundo, tal es el caso de la máscara de $V$ for Vendetta (Biekart \& Fowler, 2013; Munro, 2015; Pleyers \& Glasius, 2013).

Se emplea en este texto el término símbolos en el sentido que plantea Thompson (2002) en el análisis de las formas simbólicas, como elementos significativos que se producen y son interpretados por los sujetos en contextos específicos.

La vida social no es sólo una cuestión de objetos e incidentes que se presentan como hechos en el mundo natural: también es una cuestión de acciones y expresiones significativas, de enunciados, símbolos, textos y artefactos de diversos tipos, y de sujetos que se expresan por medio de éstos y buscan comprenderse a sí mismos y a los demás mediante la interpretación de las expresiones que producen y reciben (p. 183).

Esto último no puede comprenderse al margen de la articulación entre elementos de cultura mediática y expresión pública. De acuerdo con Thompson (1995), los medios han sido parte central del nacimiento y crecimiento de las sociedades modernas, desde la invención de la imprenta hasta la comunicación digital. Se trata de instituciones clave para la construcción de la realidad, en tanto que los contenidos mediáticos "representan" el mundo (Couldry, 2012). Por un lado, los medios contribuyen a construir sentido del mundo mediante la información sobre acontecimientos localizados, ante un público global. Por otro lado, los sujetos acceden a cada vez más recursos mediáticos, que dan forma -en gran medida - a su experiencia cultural (Thompson, 2002). En ese sentido, la cultura mediática, que se construye en y a partir de productos de la radio, la televisión, la música, el cine y las redes digitales, provee de recursos para construir visiones del mundo e identidades (Kellner, 2011).

Lo anterior se traduce en prácticas específicas. En términos amplios, las prácticas pueden entenderse como "los procederes situados de un sujeto" (Giddens, 1987). De modo más específico, Couldry (2012) habla de prácticas mediáticas. Señala que éstas son regulares, en tanto que se incorporan en la vida cotidiana, como actividades rutinarias, que se realizan con cierta regularidad. Son también sociales, incluso si son ejercidas por sujetos individuales, ya que refieren a un contexto social más amplio, habilitante y constrictivo. Se relacionan con las necesidades humanas, que apelan a elementos sociales, políticos, económicos. Además, las prácticas permiten observar la dimensión normativa de los medios, porque en ellas se observa cómo los sujetos viven con los medios y cómo piensan que deberían hacerlo.

En la propuesta de Couldry (2012), las culturas mediáticas pueden ser comprendidas en torno a las necesidades económicas, étnicas, políticas, de reconocimiento, de creencias, sociales y de ocio. En este trabajo, es importante considerar y distinguir las necesidades políticas y de reconocimiento. Las primeras se refieren a la presencia de actores políticos en los medios, si bien los más evidentes son las autoridades gubernamentales, la ciudadanía también requiere contar con canales para expresarse. Las necesidades de reconocimiento se refieren a la búsqueda de los grupos sociales por ser reconocidos y respetados entre ellos, con y por los otros. La discusión sobre el reconocimiento —que proviene de la filosofía política- aboga por una relación recíproca ideal entre sujetos, donde es posible comprender que el otro es diferente y tiene derecho a serlo, a la vez 
que es o debe ser igual en cuanto a derechos. En ese sentido, el reconocimiento es más un horizonte normativo que una realidad (Fraser, 2008; Honneth, 2011).

El siguiente elemento es la resonancia. En los estudios de medios, Schudson (1989) la entiende como una dimensión del poder cultural, que se refiere al grado en el cual un objeto cultural resuena en la audiencia, es decir, se vuelve relevante y se conecta con ella. Estas conexiones se sitúan en los marcos culturales comunes de los que se hablaba en párrafos anteriores. Ettema (2005) enfatiza que la resonancia proviene de los procesos de producción de mensajes.

En el estudio de los movimientos sociales, la resonancia define la experiencia por la cual los sujetos, que pueden estar geográficamente distantes, se identifican y comprometen en torno a luchas políticas y sociales concretas, que les resultan significativas en sus propios lugares (Khasnabish, 2007). Se asume que algunos recursos culturales resuenan más que otros, en tanto que se vuelven relevantes para los movimientos $y$, sobre todo, juegan un papel central en la proyección de estos en lo público (Williams, 2004).

En este sentido, la resonancia se refiere a un proceso no lineal que consiste en hacer nuevas conexiones políticas a partir del encuentro con el otro. Se trata de un nuevo entendimiento de la acción política, la lucha y la posibilidad (Khasnabish, 2007). Se produce, entonces, un sentido de lucha compartida, que opera mediante símbolos, emociones y valores, que tienen un sentido político y se orientan hacia el futuro (Pleyers \& Glasius, 2013). En estos procesos, los medios digitales operan como una especie de "tejido conectivo", que facilita la resonancia en contextos geográficos distantes, al posibilitar las conexiones entre actores alrededor del mundo (Khasnabish, 2007; Pleyers \& Glasius, 2013). Por ello, para los movimientos, resulta muy relevante la posibilidad de acceder a la expresión pública.

En esta línea, la expresión pública se deriva de las discusiones contemporáneas sobre lo público y sus reconfiguraciones, primero por la incorporación de los medios de comunicación $y$, después, por la emergencia de internet. En los estudios de medios se enfatiza el rol central que estos juegan en las sociedades democráticas de la modernidad. Sin embargo, se reconoce que el acceso a lo público no ha sido precisamente democrático. Una de las principales trabas es la tendencia creciente a la privatización, mediante la concentración de la propiedad mediática en unas pocas corporaciones transnacionales, con las implicaciones que eso tiene en términos de centralización en la producción de contenidos, control de la información, riesgos para la privacidad y más (Castells, 2009; Couldry, 2008; McQuail, 2010; Thompson, 2011). A esto hay que sumar la exclusión sistemática de ciertos sectores sociales del acceso a lo público, que tiene implicaciones políticas (Saintout, 2011, 2019).

La emergencia de internet fue leída por muchos como una alternativa que permitiría desafiar las lógicas de los medios masivos, al construirse como un espacio más democrático y libre. Si bien en nuestros tiempos hay elementos para contradecir estas concepciones de horizontalidad, democracia y libertad en la red, se reconoce que en ésta se ha posibilitado el acceso de nuevos actores a lo público.

Si bien la expresión pública puede materializarse de distintas maneras, una de las vías principales en nuestros tiempos es a través de los medios digitales. Para los activistas, las redes son una posibilidad para ampliar la visibilidad y desafiar los marcos 
dominantes de hacer sociedad, cultura y política (Cardon, 2011; Lievrouw, 2011). En este marco, defino la expresión pública digital como la participación de los sujetos en lo público, mediante la producción, remediación, distribución, intercambio, consumo e interacción, a través de medios digitales, para visibilizar determinadas problemáticas y/o visiones del mundo (Flores-Márquez, 2019).

Las prácticas de expresión pública de los activistas tienen un carácter transformacional, en tanto que se orientan al cambio social. En ellas es posible identificar la formación de cierto tipo de estéticas. Para Rancière (2009), la estética se refiere al reparto de lo sensible, esto es, una distribución de los recursos culturales que está ligada con las diferentes posiciones que los sujetos tienen en lo común, de manera que:

Una figura no es simplemente una palabra o una imagen en lugar de otra. Se puede ampliar el proceso: es también un medio para otra cosa, una manera de producir sensibilidad y sentido en un lugar otro, un espacio nuevo constituido por estas sustituciones (Rancière, 2014, p. 82).

La estética, entonces, tiene un sentido político, que se observa de modo particular en el activismo. En esta lógica, Leah Lievrouw (2011) habla de medios alternativos/activistas, para referirse a los modos en que los activistas apropian de distintas maneras los medios digitales, con el fin de hacer frente a los marcos dominantes. De acuerdo con esta autora, el surgimiento de estos medios se vincula con el arte activista, especialmente el dadaísmo - desde la época de la Primera Guerra Mundial- y la Internacional Situacionista — desde las décadas de 1950 y 1960-. Estos representaron rupturas estéticas clave en el siglo XX, al combinar la política radical con usos provocadores de los medios, la performance y el lenguaje.

Esta autora define a los medios alternativos/activistas como aquellas iniciativas que emplean o modifican los medios de comunicación y las prácticas mediáticas, para desafiar o alterar los modos dominantes, esperados o aceptados, de hacer sociedad, cultura y política. Se trata, entonces, de poner en circulación visiones críticas del mundo, a través de recursos digitales (Lievrouw, 2011). En este marco, los medios digitales son espacios de disputa por el sentido, en los cuales los sujetos acceden a recursos de simbolización y expanden sus posibilidades de visibilidad (Cardon \& Granjon, 2010; Cardon, 2011; Flores-Márquez, 2019; Lievrouw, 2011; Milan, 2013).

Lievrouw (2011) propone cinco géneros de proyectos de medios alternativos/activistas: la intervención cultural, la computación alternativa, el periodismo participativo, la movilización mediada y el conocimiento común. La intervención cultural consiste en la apropiación creativa, irónica y subversiva de elementos de la cultura popular, para crear obras de arte con un sentido político. La computación alternativa se refiere a los esfuerzos de producción de software y hardware, por fuera de los canales comerciales. Esto incluye los mecanismos para burlar la vigilancia y la censura, para encriptar los datos y para proteger los derechos digitales, de privacidad y libertad de expresión. El periodismo participativo comprende a los proyectos de medios alternativos o radicales, que se oponen a los medios mainstream. Un ejemplo de ellos es Indymedia. La movilización mediada es la utilización de tecnologías digitales para conformar redes, para organizar política y culturalmente las movilizaciones sociales, tanto presenciales como digitales. Finalmente, el conocimiento común considera las iniciativas activistas que cuestionan los saberes expertos $y$, frente a ello, plantean proyectos independientes de producción y difusión del conocimiento, como es el caso de Wikipedia. 
Para este trabajo, resulta relevante la articulación entre la movilización mediada y la intervención cultural, que se observa en las movilizaciones de los años recientes, mediante la utilización de diferentes símbolos. En las siguientes dos secciones, se hace un recuento de ellos, tanto en la lógica de apropiación, como en la de creación.

\section{Apropiación de símbolos en el activismo}

La máscara de Guy Fawkes es uno de los símbolos que se han utilizado en el activismo a lo largo de varios años, en diferentes partes del mundo. Guy Fawkes fue un insurgente que atacó al Parlamento Británico en 1605. Su imagen ha estado presente en varias novelas, pero su mayor difusión mediática se dio con la película $V$ for Vendetta, la cual fue dirigida por James McTeigue en 2005 (IMDb, 2005). La máscara fue apropiada como símbolo de resistencia en diferentes momentos. Primero, el colectivo hacktivista Anonymous la adoptó en 2008, en el Project Chanology, que hacía frente a la iglesia de la cienciología. Posteriormente, en 2011, fue utilizada por manifestantes en Occupy Wall Street y en otras protestas en los países del norte de África, en la Primavera Árabe. Ha sido también utilizada en marchas en Tailandia, Turquía, México y, recientemente, en Hong Kong (AFP, 2019; Jones, 2011; Nickelsburg, 2015; Ough, 2015).

En 2014, en las manifestaciones juveniles en Tailandia contra el golpe de Estado, algunos estudiantes utilizaron el saludo con tres dedos y el brazo extendido, que se hacía en Hunger Games, la saga literaria y cinematográfica, escrita por Suzanne Collins y dirigida por Gary Ross (IMDb, 2012). Los manifestantes adoptaron este saludo como desafío al gobierno militar. Uno de los activistas tuiteó: “Dear \#HungerGames. We've taken your sign as our own. Our struggle is non-fiction. Thanks" (Queridos \#HungerGames. Hemos tomado su señal como propia. Nuestra lucha no es ficción. Gracias) (Brzeski, 2014; Mydans, 2014).

En 2017, el día de la toma de posesión de Donald Trump como presidente de los Estados Unidos de América fue también la Marcha de las Mujeres. En ella, además de la PussyHat - que se aborda en la siguiente sección-, uno de los símbolos más recurrentes fue la imagen de la princesa Leia (ver figura 1), de Star Wars, con leyendas como "we are the resistance" ("somos la resistencia"), "we are the force" ("somos la fuerza") y "a woman's place is in the resistance" ("el lugar de una mujer está en la resistencia") (Loughrey, 2017; Watercutter, 2017; Williams, 2017). Estas protestas se replicaron un año más tarde (Guo, 2018).

En 1985, la escritora canadiense Margaret Atwood publicó la novela The Handmaid's Tale. En la historia se plantea una sociedad distópica, a partir del golpe de un grupo político radical que convirtió a Estados Unidos en Gilead, un Estado conservador y patriarcal, particularmente violento con las mujeres. La novela ha tenido varias adaptaciones a distintos formatos. La más exitosa de ellas ha sido la serie que lleva el mismo nombre, que se transmite desde 2017 a través de Hulu (IMDb, 2017). En la historia, June, la protagonista y otras "criadas" o esclavas sexuales, visten de rojo, con un sombrero blanco. Esta vestimenta ha sido empleada en protestas feministas, principalmente en aquellas que luchan por los derechos sexuales y reproductivos, en Canadá, Estados Unidos, Argentina, Reino Unido, Irlanda, Croacia y Polonia (Beaumont \& Holpuch, 2018; Bell, 2018; Hauser, 2017). 


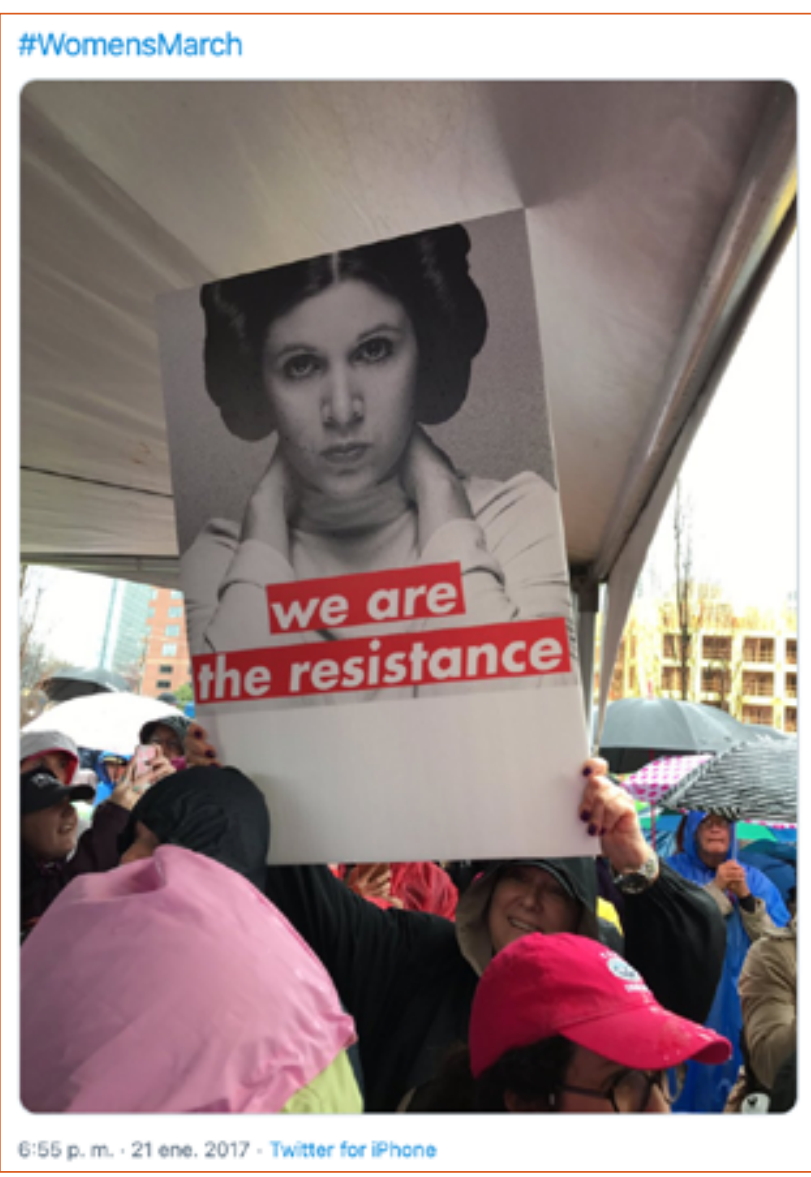

Figura 1. \#WomensMarch.

Fuente: @IBexWeBex (21 enero 2019)
También en 2017 se estrenó la serie española La Casa de Papel, dirigida por Álex Piña. La historia se transmitió inicialmente por Antena 3 en España y, posteriormente, por Netflix. En ella se aborda un atraco mayúsculo, liderado por El Profesor, para poner en jaque a los poderosos. La serie ha sido apropiada también como símbolo de resistencia. Los disfraces y máscaras que utilizan los personajes han sido empleados en las protestas en Chile, México (ver figura 2), Irak y otros países (Miranda, 2019). Además, en la serie se canta "Bella Ciao", una canción italiana que fue apropiada como símbolo de protesta anti-fascista en Europa desde mediados del siglo XX. Esta canción, que ya había sido empleada en protestas recientes como la Nuit Debout en Francia, ha sido retomada en 2019 a partir de la popularidad de la serie. Así, algunos manifestantes colombianos cantaron "Duque ciao, Duque ciao, Duque ciao" para pedir la renuncia del presidente Iván Duque, mientras que en Irak se ha escuchado también en las protestas contra la corrupción (Carrión, 2019; La República, 2019).

En 2019, llegó a las salas cinematográficas Joker, la película dirigida por Todd Phillips y protagonizada por Joaquin Phoenix, donde se presenta una historia alternativa del anti-héroe de Batman. En la historia, se observan protestas ante la desigualdad social que hay en Gotham City. Unos días después del estreno, la imagen de este personaje apareció en protestas en Chile, Ecuador, Líbano, Argelia y Hong Kong (Apro, 2019; Blánquez, 2019; Gutiérrez, 2019; Mounier, 2019; Schmitt-Tegge, 2019).

Estas experiencias permiten observar la utilización de elementos de la cultura mediática, con los cuales las y los activistas se identifican, los apropian y resignifican en su expresión pública.

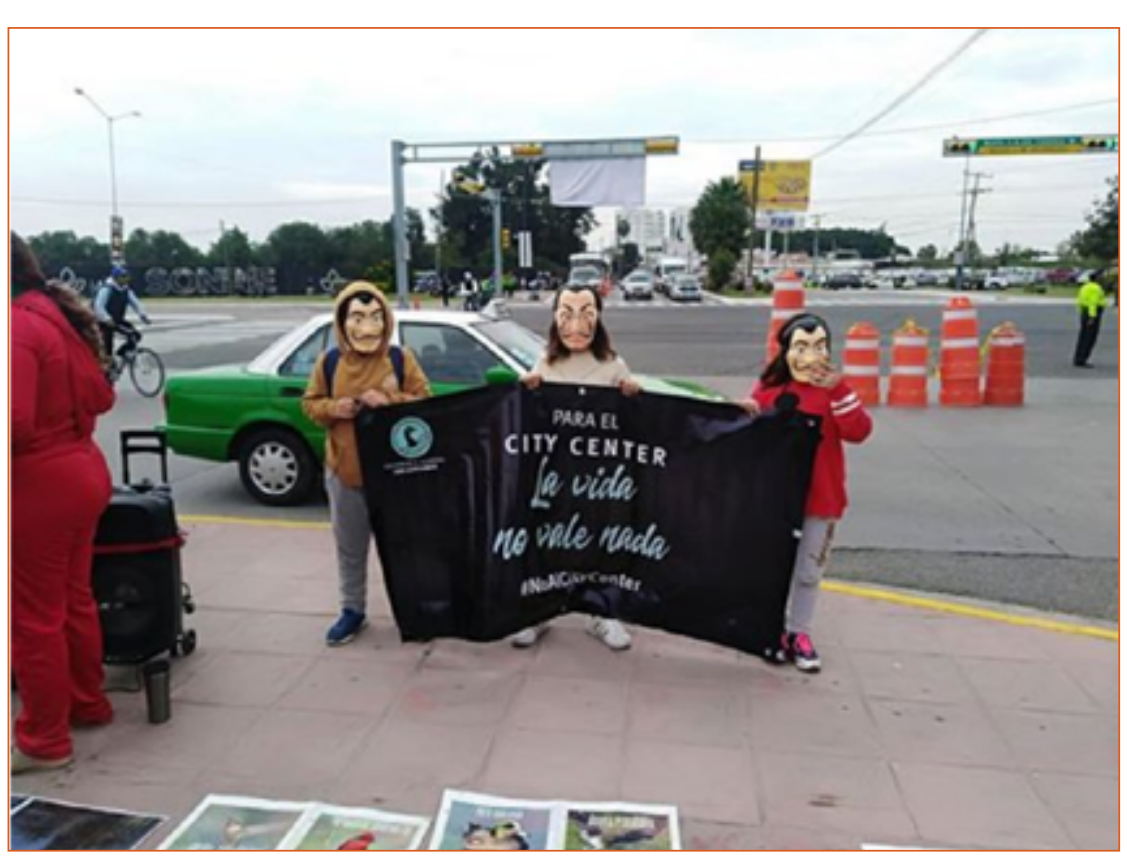

Figura 2. Fuente: Salvemos El Humedal Los Cárcamos, León, Guanajuato (17 Noviembre 2019) 


\section{Creación de símbolos en el activismo}

En los años recientes, hemos visto también el surgimiento de distintos símbolos de la protesta alrededor del mundo. Desde 2003, las feministas argentinas emplean los pañuelos verdes en las manifestaciones en favor de las legislaciones que permitan el aborto (Camacho, 2019). A partir de 2014, los manifestantes en Hong Kong han empleado sombrillas amarillas, para protegerse de la vigilancia, los gases lacrimógenos y, a la vez, como símbolo (Whiteaker, 2019). A finales de 2018, las protestas contra la violencia del Estado francés se conocieron como Gilet Jaunes (chalecos amarillos). Los manifestantes han usado justamente los chalecos amarillos de seguridad, que son empleados para aumentar la visibilidad y evitar accidentes. En la práctica, estos accesorios se volvieron el símbolo y el nombre del movimiento (Pezet, 2019). En 2019, en México, en las marchas para exigir justicia ante la violencia contra las mujeres, la diamantina rosa se volvió un símbolo también, luego de que una manifestante la lanzara a un funcionario de gobierno, en el marco de manifestaciones contra los feminicidios (Camacho, 2019).

En la Marcha de las Mujeres, que tuvo lugar en 2017 en Washington y otras ciudades de Estados Unidos, el mismo día de la toma de protesta presidencial en Estados Unidos, se popularizó la PussyHat. Frente a las declaraciones misóginas que había hecho Donald Trump cuando era candidato, algunas activistas feministas invitaron a usar Pussyhats, unos gorros tejidos, color rosa, que hacían alusión a las mujeres, tanto por el color rosa asociado a lo femenino, como por la referencia a la vagina (Hartocollis \& Alcindor, 2017; PussyHat Project, 2019).

A finales de octubre de 2019, se hizo viral la fotografía de una bailarina con la bandera de Chile. El país se estremecía con las protestas detonadas por el aumento en las tarifas del transporte público, que visibilizaron el hartazgo de los chilenos frente a la desigualdad económica. Los fotógrafos María Paz Morales y Oscar Seguel Mangiola hicieron una sesión con la bailarina Catalina Duarte, para reflexionar sobre la realidad social (Pineda, 2019; Rodríguez, 2019). La imagen se volvió un emblema de la lucha (ver figura 3).

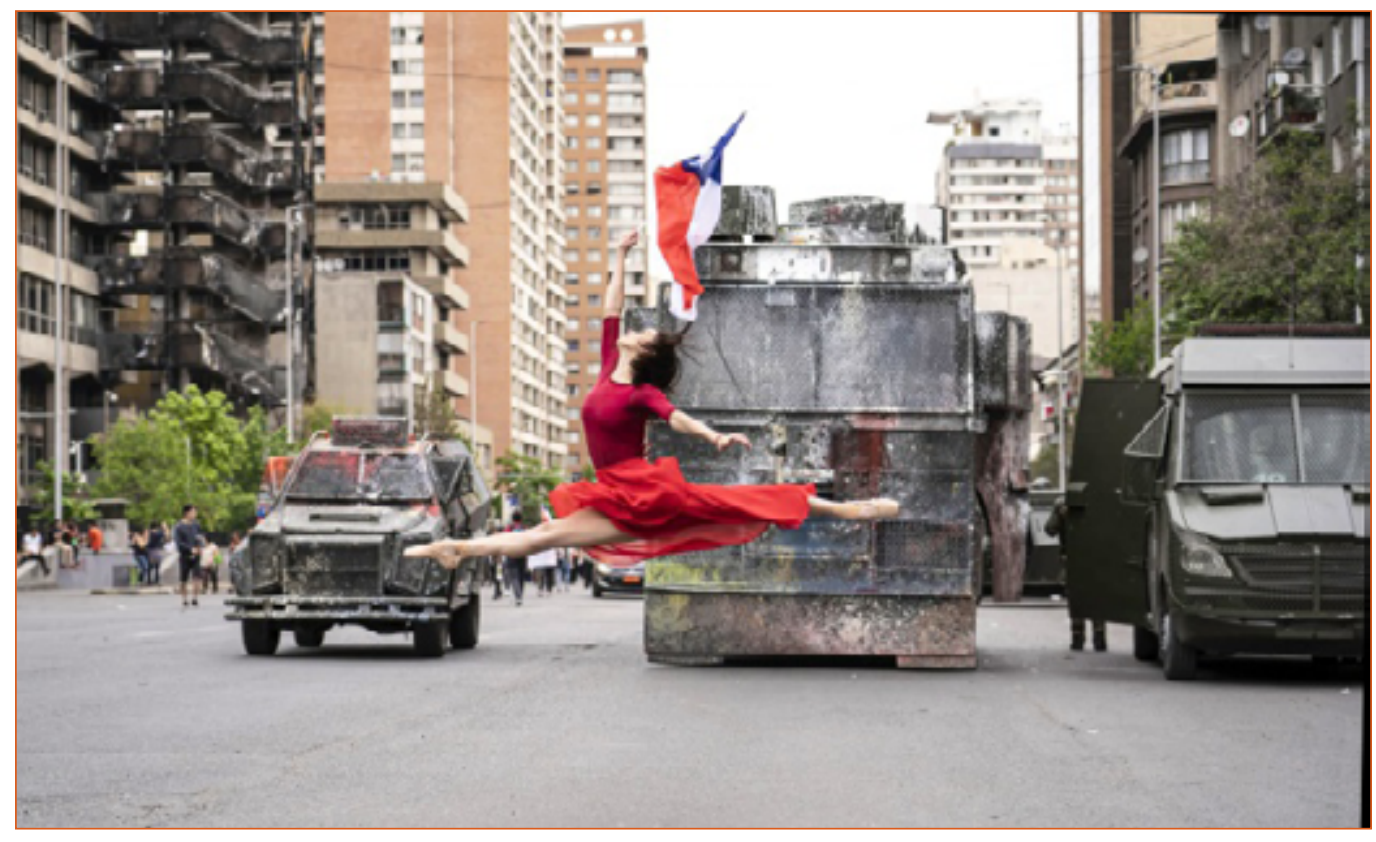

Figura 3. "Con Catalina, en la histórica Gran marcha de Chile". Fuente: María Paz Morales (@pazpachy). 
Esto evoca algo que ya había ocurrido en New York, en 2011, cuando Adbusters difundió un cartel al que se atribuye el inicio de Occupy Wall Street. En él se aprecia una bailarina de ballet, sobre la escultura del toro que simboliza a Wall Street (ver figura 4). En la parte superior de la imagen hay una pregunta: "What is our one demand?" En la parte inferior, hay una invitación: "\#OccupyWallstreet September 17th. Bring tent" (Beeston, 2011; Bierut, 2012; Yardley, 2011).

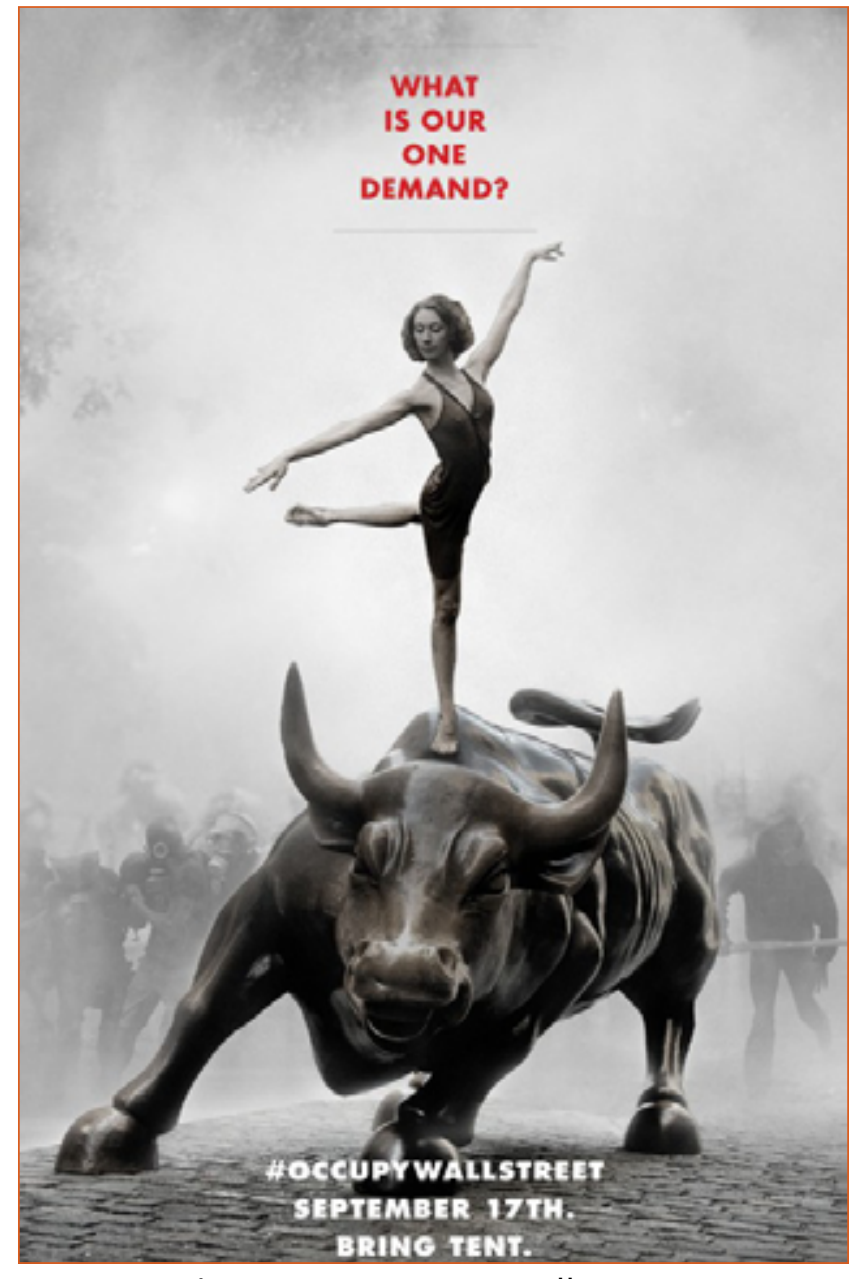

Figura 4. \#OccupyWallStreet.

Fuente: Adbusters. Julio 2011.
Uno de los casos más recientes, que además ha tenido impacto global, es la performance "Un violador en tu camino". La autoría inicial es del colectivo chileno Las Tesis, que preparaba una puesta en escena para representar artísticamente algunas propuestas teóricas feministas. Ellas hicieron la primera presentación en el marco de unas intervenciones callejeras, el 20 de noviembre de 2019, en Valparaíso, Chile. Unos días después, el 25 de noviembre, el Día Internacional de la Eliminación de la Violencia contra las Mujeres, se presentó en Santiago (Flagos, 2019). A través de las redes, se hizo viral el cántico de "y la culpa no era mía, ni dónde estaba ni cómo vestía, el violador eres tú". Además de la letra, la performance juega con otros elementos simbólicos como la venda negra en los ojos, los pañuelos verdes y la ropa (Agostini, 2019).

Pronto comenzó a replicarse en diferentes ciudades, de países como México, Colombia, Perú, Brasil, España, Francia, Alemania, Reino Unido y la India $(A P, 2019$; Barragán \& Rodríguez, 2019; EFE, 2019; EI

País, 2019; McGowan, 2019; Muñoz Lima, 2019), así como en Turquía. En este último caso, la performance en la calle fue reprimida por la policía, pero fue replicada por las legisladoras en el Parlamento, para hablar "por las que no pueden hacerlo en la calle" (BBC News Mundo, 2019; Mourenza, 2019). En palabras de una de sus creadoras: "se nos escapó de las manos y lo hermoso es que fue apropiado por otras" (Pais, 2019). La resonancia de esta propuesta trascendió países, edades, niveles socioeconómicos, idiomas y legislaciones. La reflexión que ellas hacen ante el fenómeno fue publicada en un manifiesto, donde enfatizan:

Lo colectivo te permite articular a las personas en el mundo [...]. Esa respuesta, para nosotras, se traduce en la lectura de experiencias de mujeres que han sido abusadas, que han sido violentadas, que han vivido violencia política sexual [...]. Por otro lado, también es devastador ver que las problemáticas que se tratan en esta canción siguen aún hoy siendo transversales a nivel social, aquí y un poco en todos lados (Las Tesis, 2019). 
La creación de símbolos trasciende los contextos localizados y se conecta con otros, al darse a conocer principalmente a través de los medios digitales. La identificación tiene que ver con las problemáticas comunes que se viven alrededor del mundo, tales como la violencia de género, la desigualdad y otras. Este recuento recupera algunos casos relevantes de apropiación y creación de símbolos en el activismo. Se trata de una revisión parcial, dado que hay más símbolos utilizados en mayor o menor medida en las manifestaciones. Sin embargo, es un buen ejemplo de la utilización de estos para la reflexión.

\section{Estéticas activistas}

En los casos observados, tanto de apropiación como de creación de símbolos, hay un vínculo claro con la cultura mediática. Por un lado, buena parte de los símbolos apropiados provienen de los medios. Tal es el caso de los personajes de Star Wars, $\checkmark$ for Vendetta, La Casa de Papel o Joker, así como el saludo de Hunger Games y otros elementos. Las audiencias asocian estos símbolos con posiciones de resistencia a partir de las narrativas mediáticas, los retoman y los emplean en las manifestaciones como una manera de expresar públicamente su acuerdo en torno a determinadas ideas. Esto opera como una expresión simbólica de una posición política y, a la vez, como una búsqueda creativa del reconocimiento de tales posiciones. La cultura mediática, compartida globalmente, permite identificarse con los elementos puestos en juego, lo que facilita la resonancia de las ideas en torno a problemáticas globales, experimentadas en contextos locales. Tales conexiones sostienen el encuentro con el otro, sea este cercano o distante.

Por otro lado, los símbolos creados expresamente para las movilizaciones se emplean presencialmente en ellas, pero también se difunden a través de los medios digitales, como una acción de expresión pública sobre un tema o acontecimiento específico. En la lógica de la cultura mediática, la circulación de estos símbolos permite identificarlos tanto en sus contextos de origen como fuera de ellos. En algunos casos, el símbolo remite a algo específico, tal como ocurre con la bailarina chilena o la de Occupy Wall Street. En otros, los símbolos creados en un lugar son apropiados, replicados y a veces transformados en otros, como ocurrió con "Un violador en tu camino" de Las Tesis.

Como fue señalado al principio, varios de los casos son muy recientes, algunos incluso siguen vigentes y en transformación al cierre de este artículo. Queda, entonces, como una limitación del trabajo la escasa distancia para el análisis. No obstante, el abordaje de estos símbolos, incluso a nivel exploratorio, contribuye a concentrar su identificación y documentación, lo cual permite a su vez abrir otras vías y preguntas de investigación.

Tanto la apropiación como la creación de símbolos configuran estéticas activistas situadas en nuestro contexto sociohistórico, vinculadas por la cultura mediática propia de la era global. La resonancia opera como una construcción de conexiones entre actores alrededor del mundo, a partir de símbolos conocidos, con los cuales los sujetos se identifican y a partir de los cuales pueden explicar creativamente sus posiciones políticas. Esto implica reconocer que la experiencia política no se limita a las vías institucionales, sino que se extiende a la vida cotidiana; que los elementos simbólicos apropiados o creados permiten dar sentido a tales experiencias y posiciones políticas.

Los medios digitales y la utilización de ellos en una lógica alternativa/activista son 
fundamentales para que los actores tengan acceso a la expresión pública, se inserten en discusiones clave, coloquen ahí sus visiones del mundo, ganen visibilidad y sostengan redes de identificación y solidaridad en torno a problemáticas específicas. Así, los medios digitales operan como un espacio de conexión y de disputa por el sentido. Estos articulan los contextos locales en torno a ciudades y eventos concretos, con el contexto global, a partir de problemáticas y preocupaciones comunes que trascienden las fronteras.

Hay por lo menos dos elementos que conviene explorar en futuras investigaciones. En primer lugar, hay coincidencias en los personajes y otros elementos de series y películas que son apropiados en las movilizaciones - tales como Star Wars, The Hunger Games, The Handmaid's Tale, entre otros-, ya que en ellos parece que la resistencia se enfrenta a escenarios oscuros y de desesperanza, pero al final encuentran la fuerza y la esperanza para luchar, sobrevivir y, en cierto sentido, ganar. Es pertinente analizar los vínculos entre estas narrativas de ficción y la esperanza que atraviesa los movimientos. En segundo lugar, vale la pena estudiar las maneras en que los símbolos, sean estos apropiados o creados, se erigen como elementos de imaginación política, que contribuyen a configurar las prácticas y a orientar los caminos de los participantes. Más allá de una máscara, un emblema o una serie de pasos, hay visiones sobre el futuro.

\section{Referencias}

AFP (2019, octubre 2): “Hong Kong protesters embrace 'V for Vendetta' Guy Fawkes mask”. Disponible en: https://www.hongkongfp.com/2019/10/02/hong-kong-protestersembrace-v-vendetta-guy-fawkes-masks/ [Consulta: 10 de diciembre de 2019]

Agostini, S. (2019, diciembre 10): “'Un violador en tu camino', el significado detrás de los códigos de vestimenta de esta causa feminista". Disponible en: https://www.vogue. mx/estilo-de-vida/articulo/un-violador-en-tu-camino-protesta-feminista-codigos-devestuario [Consulta: 10 de diciembre de 2019]

AP (2019, diciembre 13): "Feministas brasileñas entonan 'Un violador en tu camino"'. Disponible en: https://www.elimparcial.com/mundo/Feministas-brasilenas-entonanUn-violador-en-tu-camino-20191213-0143.html [Consulta: 10 de diciembre de 2019]

Apro (2019, octubre 31): "Se disfrazan de Joker para protestar en Hong Kong, Chile, Líbano, Beirut". Disponible en: https://www.proceso.com.mx/605424/se-disfrazande-joker-para-protestar-en-hong-kong-chile-libano-beirut [Consulta: 10 de diciembre de 2019]

Barragán, A. \& Rodríguez, D. (2019, noviembre 29): “El grito de miles de mujeres retumba en Ciudad de México con 'Un violador en tu camino'". Disponible en: https:// verne.elpais.com/verne/2019/11/30/mexico/1575076665 430100.html?fbclid=IwAR0G7fD043zaqFjfO6onu7B5RsxP6gnHbkyEBImHMbZDvcRVDB3Fi2k6I4Y [Consulta: 10 de diciembre de 2019]

BBC News Mundo (2019, diciembre 9): '“Un violador en tu camino' de Las Tesis: la policía en Turquía reprime una representación del himno feminista chileno que le ha dado la vuelta al mundo". Disponible en: https://www.bbc.com/mundo/noticiasinternacional-50715146? ocid=socialflow_facebook\&fbclid=IwAR0 711 y3yEqTdbuFGeYdShuBsUSggWZ535B_cleJnSI_IHtxbSmRj-q7TI [Consulta: 10 de diciembre de 2019] 
Beaumont, P. \& Holpuch, A. (2018, agosto 3): “How The Handmaid's Tale dressed protests across the world". Disponible en: https://www.theguardian.com/world/2018/ aug/03/how-the-handmaids-tale-dressed-protests-across-the-world [Consulta: 10 de diciembre de 2019]

Beeston, L. (2011, octubre 11): "The ballerina and the bull. Adbusters' Micah White on The Last Great Social Movement". Disponible en: https://thelinknewspaper.ca/article/ the-ballerina-and-the-bull [Consulta: 10 de diciembre de 2019]

Bell, C. (2018, julio 27): "How the handmaid became an international protest symbol". Disponible en: https://www.bbc.com/news/blogs-trending-44965210 [Consulta: 10 de diciembre de 2019]

Biekart, K. \& A. Fowler (2013): "Transforming activisms 2010+: Exploring ways and waves", en Development and Change, vol. 44, no. 3, pp. 527-546.

Bierut, M. (2012, abril 30): "The poster that launched a movement (or not)". Disponible en: https://designobserver.com/feature/the-poster-that-launched-a-movement-ornot/32588 [Consulta: 10 de diciembre de 2019]

Blánquez, J. (2019, noviembre 19): “La sonrisa del caos: por qué el Joker se ha convertido en icono de las protestas en todo el mundo". Disponible en: https://www.elmundo. es/papel/historias/2019/11/19/5dd2cc4dfdddff46a48b4606.html [Consulta: 10 de diciembre de 2019]

Brzeski, P. (2014, junio 3): “Thailand's anti-coup protestos adopt Hunger Games salute”. Disponible en: https://www.hollywoodreporter.com/news/thailands-anti-coupprotestors-adopt-708856 [Consulta: 10 de diciembre de 2019]

Camacho, E. (2019): “Diamantina rosa, pañuelos verdes y chalecos amarillos. Desde Francia hasta Argentina, hay nuevos símbolos de protesta social". Disponible en: https://gatopardo.com/noticias-actuales/diamantina-rosa-sombrillas-chalecosamarillos-panuelos-verdes/ [Consulta: 10 de diciembre de 2019]

Cardon, D. \& F. Granjon (2010): Médiactivistes. París: Presses de la Fondation Nationale des Sciences Politiques.

Cardon, D. (2011): La démocratie internet. Promesses et limites. Paris : La Republique des Idees / Seuil.

Carrión, F. (2019, noviembre 23): “El 'Bella ciao' de La Casa de Papel, el himno viral de las protestas en Irak". Disponible en: https://www.elmundo.es/f5/ comparte/2019/11/23/5dd42d39fdddffc1698b457d.html [Consulta: 10 de diciembre de 2019]

Castells, M. (2009): Communication power. Oxford: Oxford University Press.

Couldry, N. (2008): "Media and the problem of voice". En Carpentier, N. \& De Cleen, B.: Participation and media production. Critical reflections on content creation. Newcastle: Cambridge Scholars Publishing, pp. 15-25.

Couldry, N. (2012): Media, society, world. Social theory and digital media practice. Cambridge: Polity Press.

EFE (2019, diciembre 8): “La coreografía feminista 'Un violador en tu camino' se extiende por Perú". Disponible en: https://www.efe.com/efe/america/sociedad/la-coreografiafeminista-un-violador-en-tu-camino-se-extiende-por-peru/20000013-4127876 [Consulta: 10 de diciembre de 2019] 
El País (2019, diciembre 8): “'Un violador en tu camino' llega a una India conmocionada por las últimas violaciones". Disponible en: https://elpais.com/elpais/2019/12/07/ album/1575739202 520427.html?ssm=FB MX_CM\&fbclid=IwAR34rerlFfl6v0k2nKPUPrDPj2UrSYIVAldsqCPbmP 7W5cTEpDMSBHP9pw [Consulta: 10 de diciembre de 2019]

Ettema, J.S. (2005): “Crafting cultural resonance. Imaginative power in everyday journalism", en Journalism, vol. 6, no. 2, pp. 131-152.

Flagos (2019, diciembre 11): "Quiénes son Las Tesis, el colectivo feminista chileno que creó 'Un violador en tu camino"'. Disponible en: http://www.fpd.cl/quienes-son-lastesis-el-colectivo-feminista-chileno-que-creo-un-violador-en-tu-camino/ [Consulta: 10 de diciembre de 2019]

Flores-Márquez, D. (2019): Imaginar un mundo mejor: La expresión pública de los activistas en internet. Guadalajara: ITESO.

Fraser, N. (2008): “La justicia social en la era de la política de identidad: redistribución, reconocimiento y participación", en Revista de Trabajo, no. 6, pp. 83-99.

Giddens, A. (1987): Las nuevas reglas del método sociológico. Crítica positiva de las sociologías interpretativas. Buenos Aires: Amorrortu.

Guo, E. (2018, enero 20): "At Women's March 2018, 'The Force' is strong". Disponible en: $\quad$ https://www.inverse.com/article/40385-the-force-at-women-s-march-2018 [Consulta: 10 de diciembre de 2019]

Gutiérrez, D. (2019, octubre 21): "Joker: ¿el nuevo símbolo de las protestas?" Disponible en: $\quad$ http://www.laizquierdadiario.mx/Joker-El-nuevo-simbolo-de-las-protestas [Consulta: 10 de diciembre de 2019]

Hartocollis, A. \& Alcindor, Y. (2017, enero 21): "Women's March highlights as huge crowds protest Trump". Disponible en: https://www.nytimes.com/2017/01/21/us/ womens-march.html [Consulta: 10 de diciembre de 2019]

Hauser, C. (2017, junio 30): "A handmaid's tale of protest". Disponible en: https://www. nytimes.com/2017/06/30/us/handmaids-protests-abortion.html [Consulta: 10 de diciembre de 2019]

Honneth, A. (2011): La sociedad del desprecio. Madrid: Editorial Trotta.

IMDb (2005): "V for Vendetta". Disponible en: https://www.imdb.com/title/ tt0434409/?ref_nv_sr_srsg_0 [Consulta: 10 de diciembre de 2019]

IMDb (2012): "The Hunger Games". Disponible en: https://www.imdb.com/title/ tt1392170/

IMDb (2017): "The Handmaid's Tale". Disponible en: https://www.imdb.com/title/ tt5834204/?ref_=nv_sr_srsg_0 [Consulta: 10 de diciembre de 2019]

Jones, J. (2011): “Occupy's V for Vendetta protest mask is a symbol of festive citizenship”. Disponible en: https://www.theguardian.com/commentisfree/2011/nov/04/occupymovement-guy-fawkes-mask [Consulta: 10 de diciembre de 2019]

Kellner, D. (2011): "Cultural studies, multiculturalism, and media culture". En Dines, G. \& Humez, J.M. (ed). Gender, race, and class in media. A critical reader (3rd edition). Los Angeles: SAGE, pp. 7-19.

Khasnabish, A. (2007): "Insurgent imaginations", en Ephemera. Theory \& Politics in Organization, vol. 7, no. 4, pp. 505-525. 
La República (2019, noviembre 23): “'¡Duque ciao, Duque ciao, Duque ciao, ciao, ciao!': el himno viral que exige la renuncia del presidente colombiano". Disponible en: https:// larepublica.pe/mundo/2019/11/23/colombia-manifestantes-exigen-renuncia-deivan-duque-con-cancion-de-la-casa-de-papel-video/ [Consulta: 10 de diciembre de 2019]

Las Tesis (2019, diciembre 10): “Manifiesto del Colectivo Las Tesis: la culpa no era mía, ni dónde estaba ni cómo vestía". Disponible en: https://www.theclinic.cl/2019/12/10/ manifiesto-colectivo-las-tesis-la-culpa-no-era-mia-ni-donde-estaba-ni-como-vestia/ [Consulta: 10 de diciembre de 2019]

Lievrouw, L.A. (2011): Alternative and activist new media. Digital media and society series. Malden: Polity.

Loughrey, C. (2017, enero 22): “Women's March: How Star Wars' princess Leia became a potente symbol of resistance". Disponible en: https://www.independent.co.uk/artsentertainment/films/news/womens-march-on-washington-star-wars-princess-leiacarrie-fisher-a-womans-place-is-in-the-resistance-a7539916.html [Consulta: 10 de diciembre de 2019]

McGowan, C. (2019, diciembre 6): "Chilean anti-rape anthem becomes international feminist phenomenon". Disponible en: https://www.theguardian.com/world/2019/ dec/06/chilean-anti-rape-anthem-becomes-international-feminist-phenomenon?fb clid=IwAROURQNMUBrga6Kspj6UOhdVLfzVUtj94pzyyqCN2TYUIpuNY73MjOmHdCk [Consulta: 10 de diciembre de 2019]

McQuail, D. (2010): McQuail's mass communication theory. Los Angeles: SAGE.

Milan, S. (2013): Social movements and their technologies. Wiring social change. London: Palgrave Macmillan.

Miranda, R. (2019, agosto 27): "Overoles en La Casa de Papel y el Instituto Nacional: emblemas revolucionarios y de protesta". Disponible en: https://www.eldesconcierto. cl/2019/08/27/overoles-en-la-casa-de-papel-y-el-instituto-nacional-emblemasrevolucionarios-y-de-protesta/ [Consulta: 10 de diciembre de 2019]

Mounier, J.L. (2019, octubre 25): “Desde Beirut hasta Hong Kong, el rostro del Joker brilla en las manifestaciones". Disponible en: https://www.france24.com/es/20191025beirut-hong-kong-rostro-joker-manifestaciones [Consulta: 10 de diciembre de 2019]

Mourenza, A. (2019, diciembre 16): “Diputadas turcas cantan 'Un violador en tu camino' en el Parlamento 'por las que no pueden hacerlo en la calle'". Disponible en: https:// elpais.com/sociedad/2019/12/16/actualidad/1576485012_315946.html [Consulta: 10 de diciembre de 2019]

Muñoz Lima, R. (2019, diciembre 3): “'Un violador en tu camino': ¿por qué resuena en Alemania el grito feminista chileno?" Disponible en: https://www.dw.com/es/ un-violador-en-tu-camino-por-qu\%C3\%A9-resuena-en-alemania-el-grito-feministachileno/a-51511786 [Consulta: 10 de diciembre de 2019]

Munro, W. (2015): "Adjusting the margins: Poor people's mobilization in post-Apartheid South Africa". In Epstein, I.: The whole world is texting. Youth protest in the information age. Rotterdam: Sense Publishers, pp. 137-160.

Mydans, S. (2014, noviembre 20): "Thai protesters are detained after using Hunger Games salute". Disponible en: https://www.nytimes.com/2014/11/21/world/asia/ thailand-protesters-hunger-games-salute.html [Consulta: 10 de diciembre de 2019] 
Nickelsburg, M. (2015, noviembre 5): "A brief history of the Guy Fawkes mask". Disponible en: https://www.mentalfloss.com/article/70807/brief-history-guy-fawkesmask [Consulta: 10 de diciembre de 2019]

Ough, T. (2015, noviembre 4): "Anonymous: How the Guy Fawkes mask became an icon of the protest movement". Disponible en: https://www.independent.co.uk/news/uk/ home-news/anonymous-how-the-guy-fawkes-mask-became-an-icon-of-the-protestmovement-a6720831.html [Consulta: 10 de diciembre de 2019]

Pais, A. (2019, diciembre 6): “Las Tesis sobre 'Un violador en tu camino': 'Se nos escapó de las manos y lo hermoso es que fue apropiado por otras"'. Disponible en: https:// www.bbc.com/mundo/noticias-america-latina-50690475 [Consulta: 10 de diciembre de 2019]

Pezet, J. (2019, enero 14): "Gilets jaunes: le décompte des blessés graves". Disponible en: https://www.liberation.fr/checknews/2019/01/14/gilets-jaunes-le-decompte-desblesses-graves_1702863 [Consulta: 10 de diciembre de 2019]

Pineda, P. (2019, octubre 29): "Autora de la foto viral de una bailarina frente a carros de Carabineros: 'Fue un momento de luz"'. Disponible en: https://www.meganoticias. cl/nacional/280514-maria-paz-morales-fotografa-bailarina-manifestacion-marchasantiago.html [Consulta: 10 de diciembre de 2019]

Pleyers, G. \& M. Glasius (2013): “The global moment of 2011: Democracy, social justice and dignity", en Development and Change, vol. 44, no. 3, pp. 547-567.

PussyHat Project (2017): “Our story”. Disponible en: https://www.pussyhatproject.com/ our-story [Consulta: 10 de diciembre de 2019]

Rancière, J. (2009): El reparto de lo sensible. Estética y política. Santiago de Chile: LOM Ediciones.

Rancière, J. (2014): “El teatro de imágenes". En Didi-Huberman, G., Pollock, G., Rancière, J., Schweizer, N. \& Valdés, A.: Alfredo Jaar. La política de las imágenes. Santiago de Chile: Metales Pesados, pp. 69-89.

Rodríguez, D. (2019, noviembre 24): "La historia tras la foto de la bailarina en las protestas de Chile". Disponible en: https://verne.elpais.com/verne/2019/11/23/ mexico/1574465835 743523.html [Consulta: 10 de diciembre de 2019]

Saintout, F. (2011): "Política y juventud: Transformaciones en el cruce de siglos". En Chardon, M.C.: Transformaciones del espacio público. Los actores, las prácticas, las representaciones. Buenos Aires: La Crujía Ediciones, pp. 53-64.

Saintout, F. (2019): Públicos. Aproximaciones empíricas desde la comunicación en Argentina. Buenos Aires: Editorial de la Universidad Nacional de La Plata.

Schmitt-Tegge, J. (2019, noviembre 21): "El 'Joker', ¿nuevo símbolo de protestas?" Disponible en: https://www.proceso.com.mx/605424/se-disfrazan-de-joker-paraprotestar-en-hong-kong-chile-libano-beirut [Consulta: 10 de diciembre de 2019]

Schudson, M. (1989): "How culture works. Perspectives from media studies on the efficacy of symbols", en Theory and Society, no. 18, pp. 153-180.

Thompson, J.B. (1995): The media and modernity. A social theory of the media. California: Stanford University Press.

Thompson, J.B. (2002): Ideología y cultura moderna. Teoría crítica social en la era de la comunicación de masas. México: UAM Xochimilco. 
Thompson, J.B. (2011): "Los límites cambiantes de la vida pública y la privada", en Comunicación y Sociedad, no. 15, pp. 11-42.

Watercutter, A. (2017, enero 23): "Princess Leia gave the Women's March a new hope". Disponible en: https://www.wired.com/2017/01/princess-leia-womens-march/ [Consulta: 10 de diciembre de 2019]

Whiteaker, C. (2019, septiembre 20): “The essential tool for Hong Kong protesters? Na umbrela". Disponible en: https://www.bloomberg.com/graphics/2019-hong-kongprotesters-umbrellas/ [Consulta: 10 de diciembre de 2019]

Williams, B. (2017, enero 21): "The force is strong with women marching to protest Trump". Disponible en: https://www.imdb.com/star-wars/?ref_=nv_sr_srsg_0 [Consulta: 10 de diciembre de 2019]

Williams, R.H. (2004): "The cultural contexts of collective action: Constraints, opportunities, and the symbolic life of social movements". En Snow, D.A., S.A. Soule \& H. Kriesi: The Blackwell Companion to Social Movements. Malden: Blackwell Publishing, pp. 91- 115.

Yardley, W. (2011, noviembre 27): "The branding of the Occupy movement". Disponible en: $\quad$ https://www.nytimes.com/2011/11/28/business/media/the-branding-of-theoccupy-movement.html [Consulta: 10 de diciembre de 2019] 